\title{
Cranioencephalic Malformation with Atlanto-Occipital Luxation in an Andalusian Neonate Foal
}

\author{
J. Viu, L. Armengou, E. Jose-Cunilleras, C. Cesarini, M. Pumarola, and L. Monreal
}

A 45-kg, 12-hour-old Andalusian colt was referred to the Equine Teaching Hospital of Barcelona for evaluation of abnormal mental status and weakness with inability to stand from birth. Foaling was attended and reported to be uneventful. On physical examination, the foal was recumbent and showed signs of immaturity (eg, domed forehead and flexor tendon laxity of all 4 limbs), as well as an abnormal skull characterized by a prominent occipital crest on palpation. On neurological examination, the colt was stuporous, suckle reflex was absent, and pupilary reflex of the left eye was slow and incomplete (pupilary reflex of the right eye could not be assessed because of hyphema). Oculocephalic movements were normal. The foal had tachypnea ( 80 breaths/ min) with apneic periods induced by cervical manipulation, which made assisted ventilation necessary during examination. The foal's heart rate was within normal limits ( 80 beats/min), but it had a weak arterial pulse, congested mucous membranes, and prolonged capillary refill time ( 3 seconds). All of these later signs were consistent with mild dehydration. Gastrointestinal sounds were absent and meconium impaction was detected on digital rectal palpation. Hematology and plasma biochemistry performed upon admission disclosed mildly increased lactate concentration $(4.5 \mathrm{mmol} / \mathrm{L}$; reference range, $<2.5 \mathrm{mmol} / \mathrm{L}),{ }^{1} \mathrm{PCV}(55 \%$; reference range, 40 $52 \%),{ }^{2}$ total protein concentration $(6 \mathrm{~g} / \mathrm{dL}$; reference range, $4.5-4.7 \mathrm{~g} / \mathrm{dL}),{ }^{2} \quad \mathrm{PvCO}_{2} \quad(60 \mathrm{mmHg}$; reference range, $37-43 \mathrm{mmHg})^{2}$ and bicarbonate $(26.6 \mathrm{mEq} / \mathrm{L}$; reference results, $23 \mathrm{mEq} / \mathrm{L}){ }^{2}$ and decreased glucose $(2 \mathrm{mmol} / \mathrm{L} \text {; reference range, } 6-12.5 \mathrm{mmol} / \mathrm{L})^{1}$ and potassium $(2.9 \mathrm{mmol} / \mathrm{L} \text {; reference range, } 3.5-5.5 \mathrm{mmol} / \mathrm{L})^{1}$ concentrations, which was interpreted as a mixed acidemia because of respiratory and metabolic lactic acidosis. Septic score was 12 (normal index, <11).

A cranio-cervical radiological study was performed. Images in stress position could not be taken because the foal showed apneic periods during vertical mobilization of the neck. The skull and cranial cervical vertebrae ev-

From the Servei de Medicina Interna Equina (Viu, Armengou, Jose-Cunilleras, Cesarini, Monreal) and the Unitat de Neuropatologia Veterinària (Pumarola), Departament de Medicina $i$ Cirurgia Animals, Facultat de Veterinària, Universitat Autònoma de Barcelona, Barcelona, Spain.

Corresponding author: Lara Armengou, DVM, Dipl ECEIM, Servei de Medicina Interna Equina, Departament de Medicina $i$ Cirurgia Animals, Facultat de Veterinària, Universitat Autònoma de Barcelona, 08193 Bellaterra, Barcelona, Spain; e-mail: lara.arme ngou@uab.cat.

Submitted September 25, 2009; Revised October 27, 2009; Accepted November 19, 2009.

Copyright $(02010$ by the American College of Veterinary Internal Medicine

$10.1111 / j .1939-1676.2010 .0478 . x$

\author{
Abbreviations: \\ CNS central nervous system \\ ChM Chiari malformation \\ CSF cerebrospinal fluid \\ OAAM occipito-atlanto-axial malformation
}

idenced a domed forehead, occipital crest enlargement, no articulation between occipital and atlas bones, and hypoplasic occipital condyles (Fig 1). A definitive diagnosis of malformation of the caudal cranium and atlanto-occipital luxation was reached. Because of the poor prognosis, the colt was euthanized.

Cranio-cervical radiographs in full flexion and extension, as well as collection of cerebrospinal fluid (CSF) from the atlanto-occipital space, were performed immediately after euthanasia. Cytological examination and lactate determination, ${ }^{\text {a }}$ as well as total protein concentration and creatine kinase activity, were performed. The liquid was clear but xanthochromic, had normal nucleated cell count and total protein concentration $(117 \mathrm{mg}$ $\mathrm{dL}$, reference range $99-120 \mathrm{mg} / \mathrm{dL}),{ }^{1}$ but creatine kinase activity and lactate concentration were increased (14 IU/ $\mathrm{L}$, reference range $0-8 \mathrm{IU} / \mathrm{L}^{1}$ and $4.4 \mathrm{mmol} / \mathrm{L}$, reference value $<4 \mathrm{mmol} / \mathrm{L},{ }^{3}$ respectively).

Postmortem myelography also was performed by injecting $25 \mathrm{~mL}$ of contrast (sodium amidotrizoate and meglumine amidotrizoate in a proportion of 10:66 in aqueous solution) in the atlanto-occipital space. Myelography in flexed-stressed position showed a $50 \%$ reduction of the subarachnoid space at the atlantooccipital junction as well as mild spinal cord compression between the $3 \mathrm{rd}$ and 4 th cervical vertebrae because of dynamic subluxation (Fig 2A and B).

At necropsy, a skull malformation was confirmed. The cranial dome was figure 8-shaped and the occipital crest was enlarged. There was caudalization of the hindbrain toward the foramen magnum. The medulla oblongata was situated between the occipital condyles, and the 4th ventricle could be seen through the foramen magnum (Fig 3). The cerebellar vermis had an S-shaped form due both to the pressure of adjacent bony structures and to the presence of hydrocephalus. In addition, there was an apparent vascular proliferation on the brain surface. Blood vessels were congested and associated with hemorrhages in the falciform and tentorium ligaments, and diffusely on the subarachnoid space. All of the ventricular system was enlarged without the presence of cellular debris in its lumen.

Histological examination of the brain was performed. Hematoxylin-eosin, immunoperoxidase, and glial fibrillary acidic protein stains were used. Microscopically, the 


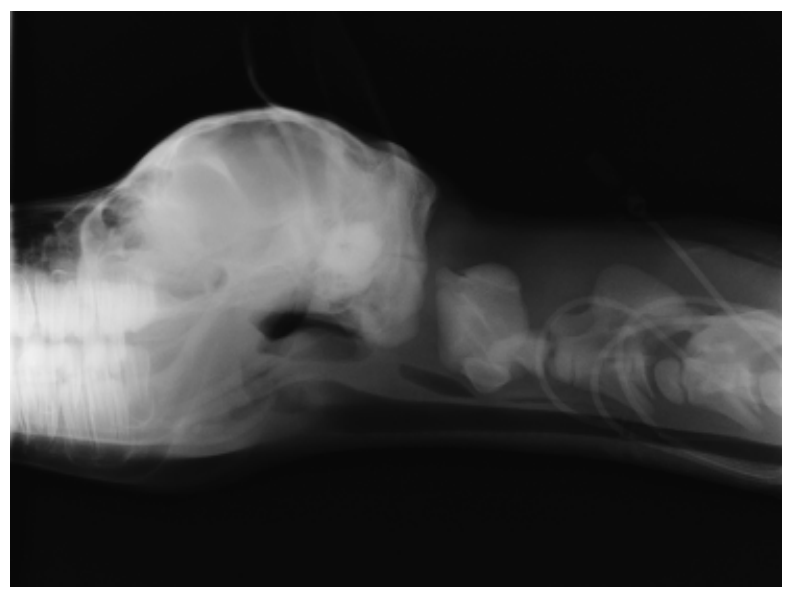

Fig 1. Postmortem radiographic image of the cranio-cervical area taken in hyperextension position. Note atlanto-occipital luxation and defectuous skull (domed forehead, hypoplasic occipital condyles, no articulation between atlas and occipital bone, and occipital crest enlargement).

brain maintained its normal histological architecture (cerebral and cerebellar cortices, basal ganglia, and brainstem). Periventricular white matter appeared com-
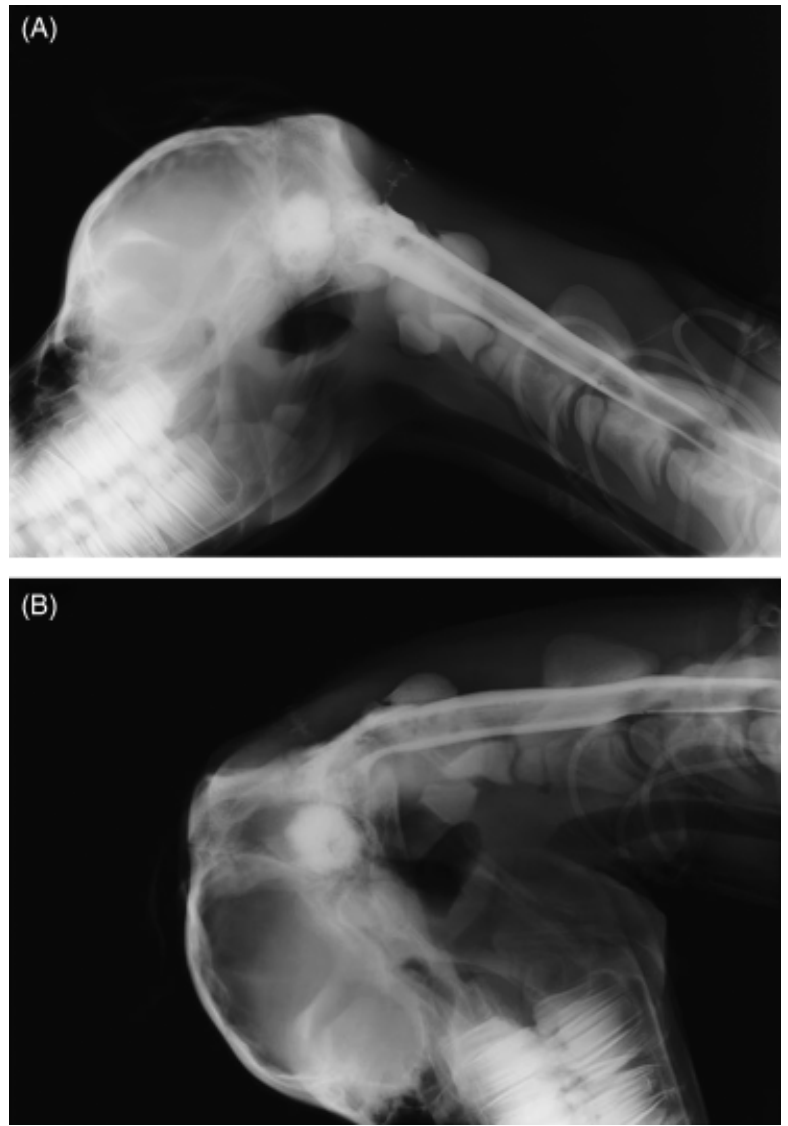

Fig 2. Postmortem myelography images on neutral (A) and flexedstress position (B). There was a marked compression, with decrease of subarachnoid contrast column at the atlanto-occipital level $(50 \%)$ with the neck in flexed-stress position (B). Another mild compression site was detected at $\mathrm{C} 3-\mathrm{C} 4$ space in both neutral and flexed-stress position (A, B).

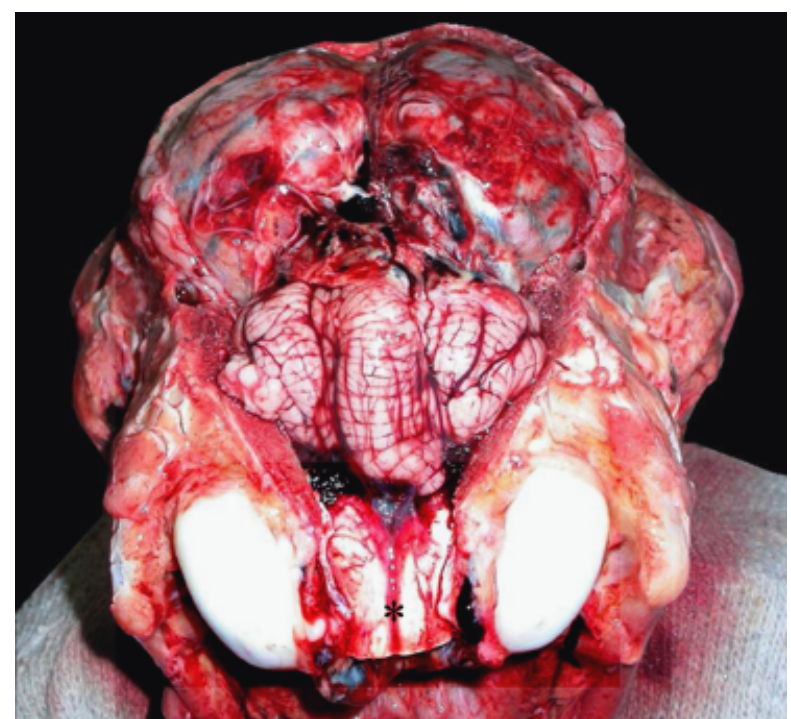

Fig 3. Hindbrain caudalization. Note medulla oblongata was situated between the occipital condyles $(*)$.

pressed especially in the cerebral hemispheres. A large number of ectopic immature neural cells were present scattered in the cerebral and cerebellar white matter, and surrounding the blood vessels of the mesencephalic tectum. A large number of medium-caliber arterioles surrounded by numerous venules were observed in all of the neural parenchyma, particularly in the leptomeninges and choroidal plexus (Fig 4). A large number of capillaries also were observed diffusely infiltrating the neuropile.

In veterinary medicine, cervical and skull congenital malformations are infrequent. ${ }^{4-6}$ In horses, occipito-atlanto-axial malformation (OAAM) is the only type of congenital malformation described affecting both skull and proximal cervical vertebrae. Other well-described congenital or developmental disorders, such as osteochondrosis dissecans, ${ }^{7}$ vertebral instability, or malalignment, ${ }^{8}$ can affect the proximal spine.

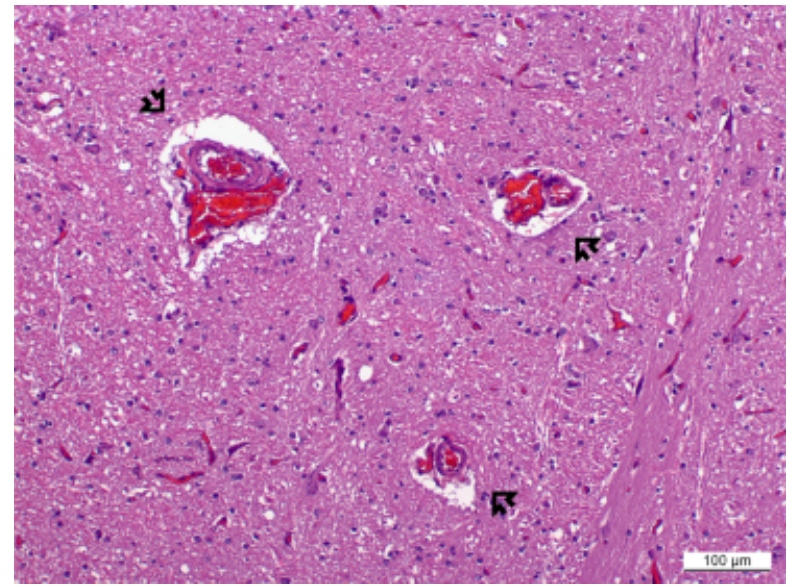

Fig 4. Medulla oblongata tissue. Sections were evaluated following hematoxylin-eosin stain. Increased numbers of medium caliber arterioles surrounded by venules (open arrows) within the nervous parenchyma are observed. 
The 1st OAAM cases in horses were reported in Arabian-bred horses in 1978. ${ }^{4}$ Four subtypes of the anomaly have been described: (1) occipitalization (occipital bonelike modification) of the atlas and atlantization (atlas bone-like modification) of the axis (familial in Arabian horses), (2) asymmetric malformations, (3) asymmetric atlanto-axial fusion, and (4) OAAM with 2 atlases. ${ }^{9}$ A 5th type describes changes similar to the familial Arabian forms in non-Arabian individuals. ${ }^{10}$ All of these conditions have some degree of fusion of the occipito-atlantoaxial bones. Congenital luxation of the atlanto-axial joint also has been described, resulting in signs of severe spinal ataxia and weakness in a neonate. ${ }^{11}$ The case reported here has several findings that are not consistent with OAAM. The malformation described in this report affects brain and skull but not cervical vertebrae. Instead of vertebral fusions, which are characteristic of OAAM, an atlanto-occipital luxation was present. Moreover, this foal also had proliferation of the vascular component of the brain that has not been described in cases of OAAM. In fact, features of the foal reported here are more consistent with Chiari malformation (ChM), a congenital alteration affecting brain and cranium and reported in human beings, ${ }^{12-14}$ calves, lambs, and recently in Cavalier King Charles Spaniels. ${ }^{5,8} \mathrm{ChM}$ is a complex of hindbrain deformities associated with spinal abnormalities and hydrocephalus, and it has been classified into 4 variations, the most frequent being types I and II. ${ }^{12}$ Type I ChM affects the cerebellar tonsils (located in the ventral portion of the cerebellum), which have shifted into the foramen magnum, but the brainstem remains in its normal anatomical position. This kind of ChM does not result in any clinical sign. In type II ChM, also called classic malformation or Arnold-Chiari syndrome, the cerebellum and brainstem are located in the foramen magnum, and the cerebellar vermis can be present or not. Generally, meningomyelocele is present. Type III is the rarest of the ChMs and results in severe neurologic findings. The cerebellum and brainstem are caudalized or herniated through the foramen magnum. In addition, there is either hypoplastic occipital bone or defects of cranium closure caused by failure of the neural tube to close completely during fetal development. Part of the 4 th ventricle of the brain also can be totally or partially herniated, and the herniated tissues can cause an encephalocele. In type IV, the cerebellum is poorly developed or not complete. ${ }^{12,13}$ Apart from other signs, types II, III, and IV can cause tetraparesis or tetraplegia as seen in the reported foal.

The congenital defects present in the foal reported here are similar to those in type II ChM. Hydrocephalus also has been described in this form of ChM because of impaired CSF drainage. ${ }^{12}$ This foal also had some features similar to those of type III ChM because it presented with hypoplastic occipital condyles.

The clinical manifestations of ChM type II are variable in human patients depending on the degree of brain dysfunction because of increased CSF pressure. Newborns with this congenital defect present with swallowing problems, arm paresis, stiff neck, and respiratory problems among other clinical signs. ${ }^{12,13,15}$ This colt had similar brain position to ChM type II and had clinical findings consistent with increased CSF volume. Although the ChM-like malformation present in this foal could explain its clinical signs, there also was severe instability of the cranio-cervical junction. Most of the respiratory controlling system is located at this medullary location, and it was likely affected by the unstable cranio-cervical luxation. In normal foals, two thirds of the brainstem central respiratory control system (dorsal and ventral respiratory groups) is located in the medulla oblongata and therefore is in an intracranial position. ${ }^{15,16}$ In the foal described here, caudalization of the medulla oblongata likely resulted in direct pressure on the respiratory centers, and was partially responsible for the respiratory signs observed during neck manipulation. This unstable spinal cord position also could worsen the tetraparesis manifested by the colt.

The cause of ChM is not yet known. One theory considers it the result of a structural defect during the fetal development. Delayed opening of Luschka and Magendie holes increases intracranial pressure and the cerebellum is pushed into foramen magnum (Gardner hydrodynamics). ${ }^{12,17}$ The hydrocephalus also can be caused by impaired CSF resorption in the absence of any CSF flow obstruction between the ventricles and subarachnoid space. This may be because of functional impairment of the arachnoid granulations, which are located along the superior sagittal sinus, the site of CSF resorption back into the venous system. Currently, the combination of both resorption absence and flow obstruction is considered to be involved in the complex etiology of pediatric hydrocephalus. ${ }^{18}$ In human medicine, ChM can be present in several family members, and it is suspected that this condition may have a genetic cause or familial predisposition. ${ }^{19,20}$ Other possible causes are vitamin deficiencies, an inappropriate diet of the mare during the pregnancy, or other lesions. ${ }^{20}$

An unusual finding of the foal in this report was the presence of vascular proliferation and ectopic immature neural cells. Vascularization of the central nervous system (CNS) is a process that occurs via angiogenesis. It coordinates the precise timing and location of multiple cell types in order to form a vascular network with CNSspecific properties. These include blood-brain barrier formation, a high degree of vascular smooth muscle cell coverage, reciprocal interactions with neurons and glia, and vascular niche for neural stem cells. ${ }^{17}$ The presence of abundant immature neural cells in an aberrant location probably reflects changes in angiogenesis pattern and also can be related to immaturity of the CNS. To the authors' knowledge, this abnormal location of neuronal stem cells in a mature brain has not been described previously.

To the authors' knowledge, this is the 1st case of Chiari-like cranioencephalic malformation in a horse. Cranio-cervical congenital malformations different from OAAM are possible in horses, resulting in severe clinical signs characterized by tetraparesis and abnormal respiratory pattern and mental status. Therefore, this type of malformation should be included in the differential diagnosis of foals presented with at least one of the signs described herein. 


\section{Footnote}

${ }^{\text {a } A c c u t r e n d ~ L a c t a t e ~ R o c h e ~ D i a g n o s t i c s, ~ B a s e l, ~ S w i t z e r l a n d ~}$

\section{References}

1. Corley K, Stephen J. Appendix. In: Corley K, Stephen J, eds. The Equine Hospital Manual. Oxford, UK: Wiley-Blackwell; 2008:654-689.

2. Knottenbelt D, Holdstock N, Madigan J. Equine Neonatology, Medicine and Surgery. London, UK: Elsevier; 2004.

3. Wong GK, Poon WS, Ip M. Use of ventricular cerebrospinal fluid lactate measurement to diagnose cerebrospinal fluid infection in patients with intraventricular haemorrhage. J Clin Neurosci 2008;15:654-655.

4. Mayhew IG, Watson AG, Heissan JA. Congenital occipitoatlantoaxial malformations in the horse. Equine Vet J 1978;10: $103-113$.

5. Rusbridge C, Knowler SP. Coexistence of occipital dysplasia and occipital hypoplasia/syringomyelia in the Cavalier King Charles Spaniel. J Small Anim Pract 2006;47:603-606.

6. Schmidt SP, Forsythe WB, Cowgill HM, et al. A case of congenital occipitoatlantoaxial malformation (OAAM) in a lamb. J Vet Diagn Invest 1993;5:458-462.

7. Beck C, Middleton D, Maclean A, et al. Osteochondrosis of the second cervical vertebra of a horse. Equine Vet J 2002;34: 210-212.

8. Mayhew IG. Congenital, genetic, and familial disorders. In: Mayhew IG, ed. Large Animal Neurology, 2nd ed. Oxford, UK: Wiley-Blackwell; 2009:183-225.
9. de Lahunta A, Hatfield C, Dietz A. Occipitoatlantoaxial malformation with duplication of the atlas and axis in a half Arabian foal. Cornell Vet 1989;79:185-193.

10. Wilson WD, Hughes SJ, Ghoshal NG, et al. Occipitoatlantoaxial malformation in two non-Arabian horses. J Am Vet Med Assoc 1985;187:36-40.

11. Witte S, Alexander K, Bucellato M, et al. Congenital atlantoaxial luxation associated with malformation of the dens axis in a Quarter Horse foal. Equine Vet Educ 2005;17:175-178.

12. Caldarelli M, Rea G, Cincu R, et al. Chiari type III malformation. Childs Nerv Syst 2002;18:207-210.

13. Botelho RV, Bittencourt LR, Rotta JM, et al. Adult Chiari malformation and sleep apnoea. Neurosurg Rev 2005;28:169-176.

14. Healey D, Letts M, Jarvis JG. Cervical spine instability in children with Goldenhar's syndrome. Can J Surg 2002;45:341-344.

15. Nogues MA, Roncoroni AJ, Benarroch E. Breathing control in neurological diseases. Clin Auton Res 2002;12:440-449.

16. Nogues MA, Benarroch E. Abnormalities of respiratory control and the respiratory motor unit. Neurologist 2008;14:273288.

17. Mancuso MR, Kuhnert F, Kuo CJ. Developmental angiogenesis of the central nervous system. Lymphat Res Biol 2008;6:173-180.

18. Beni-Adani L, Biani N, Ben-Sirah L, et al. The occurrence of obstructive vs absorptive hydrocephalus in newborns and infants: Relevance to treatment choices. Childs Nerv Syst 2006;22:15431563 .

19. Milhorat TH, Bolognese PA, Nishikawa M, et al. Syndrome of occipitoatlantoaxial hypermobility, cranial settling, and Chiari malformation type I in patients with hereditary disorders of connective tissue. J Neurosurg Spine 2007;7:601-609.

20. Hurlbert R, Fehlings M. The Chiari malformations. In: Engler G, Cole J, Merton W, eds. Spinal Cord Diseases: Diagnosis and Treatment. New York: Marcel Dekker Inc; 1998:65-100. 